\section{Ritual e performance nas artes indígenas ${ }^{1}$}

\author{
Regina Polo Müller ${ }^{2}$
}

\section{Arte total e performatividade}

Abordar rituais nas sociedades indígenas é tratar de performances cênicas, nas quais diferentes linguagens se integram: dança, música, artes plásticas (adereços, objetos, pintura corporal), teatro ( ritos e incorporação de personagens), literatura (narrativas míticas, discursos rituais) e cenografia ( organização espacial para a ação ritual).

Pode-se definir o ritual, segundo Turner, como o modo pelo qual um complexo de ações performáticas e meios de comunicação sensorial, visual e sonora, de grande variabilidade, faz emergir significados que permitem o exercício da reflexividade sobre a experiência social. A dimensão estética do ritual se encontra, deste ponto de vista, no entendimento de que sua relação com um sistema social ou configuração cultural não é de meramente refleti-los ou expressá-los, unidirecionalmente, mas sim de reciprocidade e reflexividade. A grande variabilidade de ação e de meios de comunicação produz um conjunto de mensagens sutilmente variáveis, resultando numa "parede de espelhos-espelhos mágicos, cada qual interpretando bem como refletindo as imagens lançadas nela, e emitidas de um para outro"(1988:24).

A dança e a música indígenas são linguagens artísticas indissociáveis que devem ser compreendidas sempre no contexto da performance ritual. A dança é a linguagem do corpo em movimento, realizada no ritmo da música, executada pelo canto ou instrumento musical ou por ambos. Em geral, a palavra para a música

1 Trabalho apresentado na Mesa 3: Exposição antropológica.

2 Antropóloga. Professora Associada. Instituto de Artes. Universidade de Campinas. vocal e a dança é a mesma: não há dança sem canto e por isso, voz e movimento constituem a materialidade dessa expressão. E esta, repetimos, se encontra contextualizada nos rituais.

Oforahai é cantar/dançar na língua dos Asuriní do Xingu, Amazônia, Brasil, povo Tupi-guarani. Trata-se do nome genérico dado às práticas rituais realizadas para promover a experiência do encontro cósmico entre o mundo dos humanos e o dos espíritos. O objetivo é garantir a vida, seja através da transmissão da substância vital que cura os pacientes do ritual Maraká, seja através da ação propiciatória que garante a caça e a boa colheita.

Ao lado dos rituais xamanísticos, ciclos de cerimônias e rituais cosmogônicos, isto é, performances cênicas dos mitos de origem, instauradores da ordem do cosmo, completam o repertório da vida ritual dos povos indígenas. A dança, linguagem do corpo em movimento, organizado esteticamente pela coreografia e pelo canto vocal, ocupa lugar fundamental no desempenho destes rituais.

A dança/música nas sociedades indígenas deve ser entendida no contexto da performance ritual e os rituais, por sua vez, como experiências sensíveis da ética e visão de mundo de um povo, sistemas expressivos através do qual se re-vive, re-cria, re-constrói, re-modela, re-elabora e reinterpreta uma cultura. Seus conteúdos dizem respeito a valores éticos e estéticos, constitutivos das cosmologias (visão de mundo) e mitologias, bem como às relações sociais e contexto histórico.

\section{Os rituais e seus contextos}

Entre os Xavante, povo Jê, habitante do Brasil Central, estado do Mato Grosso, as relações entre gêneros, entre categorias sociais 
(jovens, adultos, líderes de grupos políticos e linhagens, etc), entre grupos sociais (metades exogâmicas, grupos de idade, etc) são expressas e constituem objeto da experiência sensível nas performances rituais.

Citando Vidal\&Lopes da Silva que se baseiam em autores como Victor Turner e Clifford Geertz “... nas sociedades pré-industriais a ambição da arte é significar e não apenas representar. Por isso, a arte envolve todo um sistema de signos compartilhado pelo grupo e que possibilita a comunicação"(Vidal,1992: 281)

A música e a dança como manifestações artísticas devem ser entendidas como experiências estéticas através das quais estas sociedades realizam a formação dos indivíduos, a transmissão de saberes, o conhecimento da cosmologia e a possibilidade de se vivenciar a existência em diferentes planos do cosmo.

Moldando corpos, percepção e sensibilidade, criação e fruição estética, através de sensações que o deslocamento no espaço propicia, a experiência da dança, por exemplo, promove a superação da condição humana através da ilusão de conquista da gravidade (Langer,1980). A ornamentação corporal nos rituais KayapóXikrin, como veremos adiante, promove igualmente esta superação.

Princípios filosóficos e valores éticos e morais são assim transmitidos através da experiência estética na construção da identidade e reprodução da sociedade.

Entre os Xavante, os rituais dizem respeito a um dos sistemas de classificação social e organização social Xavante, o sistema de grupos de idade, e à relação que estabelecem com os espíritos para a obtenção da cura e dos poderes de procriação e agressividade.

A sociedade Xavante se organiza em metades exogâmicas ( os indivíduos de uma metade devem se casar com indivíduos da outra metade), grupos de idade, grupos cerimoniais, linhagens e facções políticas. $\mathrm{O}$ pertencimento dos indivíduos a estes grupos determinam comportamentos e relações sociais. Os grupos de idade classificam os indivíduos e as atividades sociais por eles realizadas são determinadas por esta classificação. $O$ grupo de idade compreende dois tipos de classificação: a de classe de idade e a de categoria de idade, simultaneamente. As classes de idade são formadas por indivíduos que viveram juntos na casa dos solteiros (hâ) durante o período que precede a iniciação, cerca de cinco anos. Existem oito classes de idade formando um ciclo contínuo de mais ou menos quarenta anos. As categorias de idade são grupos formados por indivíduos que têm em comum certos atributos reconhecidos socialmente, de acordo com seu desenvolvimento biológico, psicológico e social. Encontramos, assim, categorias de idade para os homens ( em número de oito) e para as mulheres ( em número de sete). Enquanto que o indivíduo pertence sempre a uma classe de idade, muda de categoria de acordo com as fases do ciclo de vida. Desse modo, a classe de idade à qual pertence corresponderá, no decorrer do tempo, a diferentes categorias sociais. Ou seja, as classes de idade movemse através das categorias que por sua vez, são fixas. É a combinação dos dois critérios que categoriza socialmente o indivíduo, cuja estrutura é fixa e móvel ao mesmo tempo. Dito em outros termos, um sistema de classificação cuja estrutura compreende uma ordem sincrônica e uma ordem diacrônica.

Segundo o modelo diádico construído por Maybury-Lewis ( 1974), a sociedade Xavante poderia ser apresentada como um conjunto de instituições moldadas em uma série de antíteses analógicas. Assim, o princípio que permeia o sistema de grupos de idade é dicotômico. Este princípio dá conta de relações entre o que o autor chama de classes de idade consecutivas e classes de idade alternadas, pois a antítese entre relações consecutivas e alternadas é parte dessa dicotomia. As classes de idade alternadas formam metades esportivas: uma metade é formada por homens maduros (iprèdu) e jovens iniciados('ritèy'wa) e a outra metade é formada por homens maduros na condição de responsáveis pela formação dos jovens iniciandos (dañohuy'wa) e pelos jovens iniciandos (waptè) que vivem juntos na casa dos solteiros. A corrida de toras de buriti da qual participam as duas metades esportivas, é uma manifestação simbólica da antítese entre as relações de cooperação e competição entre as classes de idade, expressões do princípio dicotômico que permeia o sistema de grupos de idade. Os membros de cada metade devem correr trazendo uma tora da 
palmeira do buriti nos ombros, passando de uns aos outros, de uma distância de $8 \mathrm{~km}$ aproximadamente de fora da aldeia para seu pátio. Os dois grupos chegam quase sempre juntos e é a boa performance dos corredores o seu objetivo . demonstração de agilidade e destreza. A relação de cooperação entre as classes de idade alternadas e a de competição entre as consecutivas é a experiência sensível proporcionada e a significação simbólica produzida por este ritual.

Se a corrida de toras é o esporte que simboliza o aspecto sincrônico do sistema de grupos de idade, ou seja, a dicotomia entre as metades, a dança daño're realizada pelos jovens iniciandos (wapté ) e os responsáveis por sua formação (dañohuy'wa), simboliza a relação de ensino e aprendizado que se estabelece entre eles, ou seja, uma relação entre gerações, as categorias de idade, como veremos a abaixo.

Daño're é o nome que se dá ao canto em geral e se trata também do ritual da dança dos wapté com seus "padrinhos" O ritual tem início na casa dos solteiros ( $h a ̂$ ), afastada da aldeia, onde todos se ornamentam. Em seguida, se dirigem à aldeia e se inicia o canto em frente às casas, ao redor da aldeia, nos dois sentidos ( leste - oeste ). Os participantes, de mãos dadas, se dispõem em círculo. Um dañohuy'wa ("padrinho") inicia o canto, os demais o acompanham e dançam olhando para o chão.

O Daño're dos jovens iniciandos e seus "padrinhos"manifesta simbolicamente a seguinte relação entre eles: os "padrinhos" são responsáveis pela preparação dos wapté para que obtenham durante este período de formação em reclusão, todas as qualidades exigidas para se tornarem indivíduos maduros e membros ativos da sociedade. Os wapté devem aprender a cantar e dançar bem, pois são atividades fundamentais no desempenho da vida social pública no que se refere às cerimônias e rituais. $\mathrm{O}$ Daño're significa este aprendizado.

Com relação aos rituais de uma maneira geral, Maybury-Lewis afirma que "Shavante are unable or unwilling to explain their own ceremonies, which makes it correspondingly difiicult to begin an analysis of them. They say simply tha they are we $d a$ literalyy 'to make beautiful' When they talk about them they discuss how the participants performed,whether for example, the boys sang well or the men ran properly"(1974:240).Para este autor , os Xavante vêm seus rituais como uma forma especial de expressão estética. Ele chama estas performances de ceremonial porque possuem uma significação simbólica que transcende a mera representação e dá exemplo da dança da-prabú na qual os executantes "....snorts and stamps and acts the part of an angry man ..." .Trata-se, segundo ele, de uma performance tradicional a qual um significado simbólico convencional é atribuído pelos demais membros da sociedade e que diz respeito a algo na ordem social que transcende o contexto particular da dança.

No ritual wai'a, grupos cerimoniais desempenham papéis que colocam em relação espíritos e humanos na obtenção dos poderes de procriação e agressividade. Assim, o contato com os espíritos dãnimite garante o poder da procriação e com os espíritos pi'u, o poder agressivo. No waiariní, ritual de iniciação ao wai'á, são três os grupos cerimoniais com diferentes papéis: os waiaté jovens iniciandos os daamawaia'wa homens maduros e os jâ'rasi'wa homens mais velhos que já foram membros dos dois grupos anteriores ( a cada 15 anos há iniciação, portanto estes últimos teriam se iniciado há aproximadamente 30 anos).Cabe aos daamawaia'wa fabricar e utilizar simbolicamente as flechas para que se realize o contato dos jovens com os poderes espirituais. A dança destacada neste ritual é o da-prabú ou dasiparabu (Giaccaria e Heide, 1972). Os daamawaia'wa a executam quase diariamente durante os dois meses da primeira fase dos ritos de iniciação ao wai'á e consiste em tentar pisar ritmicamente os pés dos inciandos, ao som do instrumento jâ (espécie de chocalho feito de cabaça), tocados pelos jâ'rasi'wa. Maybury-Lewis descreve da seguinte maneira a dança: "The men meanwhile gatherin their meeting place in the jungle and sing, emerging at intervals to 'dance at' the boys. This dance, which is characteristic oh the waia'a, is known as da-prabú (stamping on the feet).The dancer advances stamping right up to his subject and then engages in partial retrats and lunges forward.His whole posture is agressive.He adopts a scowling expression and stamps furiously, raising his knee as high as he can and pounding the earth just before the man he is 
dancing at , often pounding the latter's instep as well.He snorts and flails his arms working his shoulders in a pantomime of attack. The person who is danced at remains motionless in the ceremonial stance, eyes downcast and body relaxed. He should not move a muscle or flinch, even the dancer tramples him" (idem:257).

O Daño're e o Dasiparabu são danças rituais Xavante cujo aspecto da transmissão de valores éticos e noções da cosmologia ( espíritos cuja origem dizem respeito a outra dicotomia do ethos Xavante , as forças agressivas dos pi' $u$ e as da procriação/sexualidade dos dañimite ) pode ser enfocado através do aspecto estético - coreografia, gestual, rítmo, formação do grupo de dançarinos, etc

\section{Discurso e transcendência}

Em seu estudo sobre performances expressivas e práticas discursivas entre os Xavante, Graham analisa, da perspectiva da teoria da ação da fala, e como prática discursiva, tanto o ritual (uma performance inovadora da narrativa do sonho dirigida por um dos líderes Xavante, Warodi), como o discurso formal dos membros do Conselho dos homens maduros (warã) e a fala cotidiana na aldeia( incluindo os sons e os silêncios). A análise destas práticas, em conjunto, demonstra como, da perspectiva desta teoria, discurso, significado e intencionalidade são contextualmente situados e intersubjetivamente produzidos (1995:167).

Marcas formais do discurso Xavante como as "interações" e a "produção do texto "multivocal" (múltiplos falantes no Conselho dos Homens), são padrões encontrados no ritual que analisa e que compreendeu narrativa e dramatização de um sonho do velho líder Warodi, realizadas para a comunidade e para a própria antropóloga. É através dos sonhos, que os criadores da Humanidade ensinam o canto/dança, o qual uma vez passado aos membros do grupo, pelo líder, garantem a continuidade da sociedade Xavante. Este foi o significado explicitado por
Warodi na narrativa do sonho que acompanhou a performance ( canto/dança) do ritual da-nó're. Não apenas através do conteúdo do sonho, portanto, mas fundamentalmente, como demonstra Graham, através da ação performática é que a experiência do sonho é compartilhada com os demais membros do grupo, e com isso, a experiência dos seres humanos pertencerem à mesma categoria ontológica dos criadores, os seres imortais. Que os Xavante continuem sempre Xavante é a mensagem do sonho experienciado pelos membros da aldeia de Warodi : cantando e dançando como ensinaram os seres imortais.

Os rituais Xavante descritos se realizam com quase toda a população masculina da aldeia, tratando-se de manifestações coletivas. Os rituais xamanísticos dos Asuriní do Xingu são realizados por grupos menores, relativamente às populações em questão, pois o xamã e dois auxiliares são os principais responsáveis por sua peformance. Esta compreende a dança em frente à casa dos espíritos na aldeia, a tukaia. Desta performance poderão participar ainda jovens e crianças em determinados momentos da dança , mas diferem das danças Xavante quanto a sua estética e significado. O lugar do xamã Asuriní numa sociedade Tupi-guarani é fundamental ao realizar a metamorfose que o transporta da condição humana à de espíritos xamãs-primordiais ou de espíritos animais que povoam o cosmo Asuriní no espaço e tempo mítico. Através desse contato com os espíritos, o xamã troca substâncias: dá mingau, tabaco e recebe outras que proporcionam a cura e garantem a subsistência representada pela caça e agricultura.

Se, nos rituais Xavante, são grupos de performers que realizam a dança, no ritual xamanístico dos Asuriní, o desempenho do xamã é individual, podendo certo grupo acompanhá-lo, mas nunca a aldeia toda. Já no ritual Turé, das flautas, a participação é coletiva, dividindo-se os anfitriões e os que tocam as flautas, pareara e turiva. Trata-se de um ritual cosmogônico que atualiza mitos de origem como o primeiro ritual dos mortos, realizado para afastá-los para sempre do convívio com os vivos, a tatuagem do guerreiro e a celebração do milho. No ritual mítico, os tocadores de flautas vinham de outras aldeias, cujos habitantes eram os homemcobra, com simbolismo relacionado`a sexuali- 
dade e procriação. Os homens-cobra, tocadores de flauta convidados de outra aldeia, roubam as mulheres dos anfitriões com quem mantêm relações sexuais.

Do ponto de vista do espaço, o ritual estabelece relações cósmicas e sociais, entre categorias "diferentes" de seres, sejam sobrenaturais e humanos, sejam humanos e humanos. Durante a realização do ciclo de rituais Turé, a casa comunal se abre e juntamente com o pátio externo e a casa dos visitantes se torna o próprio cosmo no qual o mundo dos humanos se relaciona com as outras esferas cósmicas. A construção da cabana tukaia para atrair/hospedar os espíritos nos rituais xamanísticos transforma igualmente o espaço da aldeia no da convivência cósmica entre seres dos diferentes planos da realidade Asuriní. Tão importante para a reprodução social quanto os vivos da aldeia são os seres ancestrais mitológicos e os espíritos que povoam o cosmo Asuriní e participam da vivência humana, através dos rituais. Esta tendência se manifesta muito mais nitidamente no caso dos rituais xamanísticos do Maraká, estes sim, trazendo espíritos para conviverem com os humanos quase que diariamente, por exemplo, como nos períodos críticos de doenças que acometiam grande parte do grupo em toda a década de 70 , ameaçandoos de extinção.

Estudei a dança no ritual xamanístico dos Asuriní como manifestação estética e discurso construido no contexto histórico, considerando sua enunciação num determinado momento da história. Na década de 90 , pude verificar os rituais xamanísticos sendo executados com a mesma exigência estética que conjuga a dançacanto-cenografia- ornamentação corporal numa performance exemplarmente catártica de sua experiência histórica.

Os Asuriní viviam nesta época, nova situação de relacionamento com os brancos e outros índios em comparação à situação em que se encontravam, até 1985, quando sua aldeia se localizava às margens do igarapé Ipiaçava. Nesta década, com o incentivo do chefe do Posto Indígena, os Asuriní passam a organizar expedições para expulsar invasores, embargar o produto da pesca de brancos em seu território e a participar de reuniōes promovidas pelo Conselho Missionário Indigenista, órgão do Conselho de Bispos do Brasil, do movimento católico de defesa dos direitos das populações indígenas. Reivindicações junto à sociedade nacional, enfrentamento de inimigos locais e atritos com índios de outras etnias que convivem agora com eles, através de casamentos realizados, passaram a fazer parte da experiência social Asuriní. A ameaça de invasões e exploração de seu território era elaborada e expressa no discurso verbal, na situação dialógica com o interlocutor branco. Por outro lado, a experiência de convivência com seres diferentes, perigosa e ameaçadora, no plano sobrenatural e social se atualizava com a incorporação, na performance ritual, da experiência histórica do contato amistoso e ameaçador com o branco e outros índios.

Os Asuriní tinham no ritual que invocou os espíritos ferozes em 1993, uma assistência formada por brancos e outros índios que vivem na aldeia: os funcionários da FUNAI, missionários católicos e evangélicos, a antropóloga, índios Arara e Kararaô. O significado do enfrentamento e convivência, do contato amistoso e agressivo emergia na performance "da união do script com os atores e audiência num dado momento e no processo social em curso" (Turner, 1988). A ameaça da irreversibilidade de convivência com outros seres, os akaraí (brancos) e outros índios é vivida, neste caso, na ação ritual que lhe dá sentido através da experiência.

Entre os Kayapó-Xikrin, povo Jê, habitante da Amazônia, estado do Pará, os rituais mais importantes são os ligados à iniciação e à nominação. Como Vidal (1977) descreve, rituais de iniciação marcam a passagem do indivíduo do sexo masculino da fase pubertária à maturidade. Nos rituais de nominação, indivíduos dos dois sexos recebem seus nomes cerimoniais. Intimamente relacionada às atividades sazonais de caça, coleta, pesca e agricultura, a nominação pode ocorrer, por exemplo na festa do milho que por sua vez é combinada com o ritual das máscaras Kukoi (macaco prego) e Pot, (tamanduá).Desenvolvidos em várias ocasiões paralelamente . os rituais de nominação e de iniciação acompanham o ciclo anual das atividades de susbsistência durante a vida na aldeia dando expressão ritual a estas atividades. Um aspecto muito importante de qualquer ritual é a oferenda de comida a cargo do pai e da mãe, dos irmãos 
do pai e de suas esposas e outros parentes dos nominados ou iniciandos.

$\mathrm{O}$ ritual me-rêrêmê que compreende uma dança das mulheres (meni-merêrêmê) e uma dança dos homens (memu-merêrêmê) pode estar destinado à nominação e se desenvolve da seguinte maneira:

$\mathrm{Na}$ dança das mulheres, ao pôr-do-sol, elas saem em fila na praça e dançam em círculo no sentido inverso ao dos ponteiros de um relógio, durante a noite toda. Todos estão na praça central. Penduram suas redes em armações ai construídas. Um homem com prerrogativa cerimonial, sentado numa rede, dirige e acompanha os cantos, faz pequenos discursos, em tom de falsete exortando e animando as dançarinas. A dança não pode parar. Outro líder cerimonial vai à frente da fila das mulheres e canta um solo para elas. Dois líderes de uma categoria de idade de homens acompanham a dança, são os pais do maracá (chocalho que marca o ritmo), um dançando na frente e o outro, atrás. Ao amanhecer, a dança muda de ritmo, acelerando-se os passos até que a fila chegue a leste, em frente à casa dos homens. Poucos minutos antes, um líder cerimonial aproxima-se do grupo e recolhe os dois maracás. Quando a dança acaba, as mulheres voltam a suas casas, e logo se dirigem ao rio para banhar-se. Voltando do rio, tendo retornado a suas respectivas casas, é realizado um rito com seus "amigos formais" (relação social formalmente estabelecida na sociedade Xikrin entre dois indivíduos de sexo diferente ou do mesmo sexo que não são de afinidade nem de consangüinidade).Os "amigos formais" dirigem-se à casa de suas "amigas formais" e passam-lhes urncu na cabeça , cobrindo-lhes a penugem branca.

A ornamentação das mulheres compreende pintura em jenipapo (cor preta), alto da cabeça raspado à moda kayapó; espessa camada de urucu nas faces e pernas. No cabelo, trazem aplicada a penugem branca de urubu-rei.

Vidal (1992) observa que nos rituais de nominação e iniciação, a pintura corporal é complementada pela ornamentação de artefatos plumários, de cera, algodão e palha, todos fabricados pelos homens e a descreve no caso do ritual de nominação feminina nhiok, no qual há seqüência de pintura corporal e de ornamentação utilizadas por diferentes personagens. De acordo com a pesquisadora, a estampa de jenipapo das meninas nhiok, aplicadas com estilete, exprime simbolicamente a "socialização" do corpo humano. $\mathrm{O}$ uso de tintura de carvão e de pó azul da casca do ovo da ave Tinamus, pelos homens, representa um processo de transformação. No ritual de nominação feminina nhiok percebe-se a transformação da onça em gavião, assim como das nominadas em beija-flores, aptas a voar. A onça ornamenta-se e grita como o gavião, indicando que ela é especial e simultaneamente as duas coisas. As onças-gaviões auxiliam na aquisição da identidade humana e social ao possibilitarem às iniciadas a obtenção, em si, da essência das aves. Assim, o ritual afirma a existência de uma onça-gavião em um mundo que os humanos são homens aves (Giannini apud Vidal, 1992:174).

Após cada renovação da pintura de jenipapo, as crianças são pesadamente ornamentadas com brincos de madeira tingidos de urucum, colares de pecinhas de itã e miçangas, bandoleiras de algodão também tingidas de vermelho e penugem brancas de gavião-real, coladas nos cabelos. Na parte frontal da cabeça, onde foi raspado, é aplicado um desenho de linhas pretas de carvão misturado com resina, de cheiro forte, para afastar os maus espíritos. Em todos os rituais importantes, os Kayapó se enfeitam aplicando na face máscaras de pó de casca de ovo de ave Tinamus, colando nos cabelos penugens de urubu-rei e no corpo penugens de periquito e portando imponentes diademas de plumas. É o processo de transformação em aves, tal como descrito anteriormente. Em outras ocasiões vestem ainda grandes máscaras de folhas de palmeiras e entrecascas, transformando-se em macacos, tamanduás e aruanás. (idem: 176)

Essas manifestações denunciam a vontade de ultrapassar as condições da existência humana, pois os Kayapó-Xikrin do Pará se "consideram aves, profundamente insatisfeitos com sua condição apenas terrestre, impossibilitados de usufruir uma visão panorâmica- entenda-se estética- do mundo e de suas belas aldeias circulares" (Vidal, 2001:17).

Seja como "instrumentos da revelação" (Vidal, idem: ibidem), seja como "performance cultural" (Singer apud Turner, 1988) isto é, “... uma avaliação do modo pelo qual a sociedade 
lida com a história" os rituais aqui descritos e analisados constituem performances cênicas estéticamente estruturadas incluindo meios não linguísticos como a música, a dança, a arte teatral e as artes visuais- através das quais conteúdos dados da cultura ( noções e valores) a tradição ou o passado são reelaborados, num presente, com vistas a um futuro, a se garantir a continuidade e reprodução em processo.

\section{Bibliografia:}

GIACCARIA, B. \& HEIDE, A. - Xavante, Povo Autêntico, São Paulo:Editorial Dom Bosco, 1972

GRAHAM, L.R.- Performing Dreams, Discourses of Immortality among the Xavante of Central Brazil, Austin:University of Texas Press, 1995
LANGER, S. - Sentimento e Forma, São Paulo: Perspectiva, 1980

MAYBURY- LEWIS,D. - Akwe- Shavante Society. New York:Oxford University Press, 1974

MULLER, R.P.- O Corpo em Movimento e o Espaço Coreográfico: Antropologia Estética e Análise do Discurso no Estudo de Representações Sensíveis. In: NIEMEYER, A M. e GODOI, E. P. (org.) Além dos Territórios: um Diálogo entre a Etnologia Indígena, os Estudos Rurais e os Estudos Urbanos, Campinas: Mercado de Letras/Departamento de Antropologia, IFCH/UNICAMP, 1998

TURNER, V.- The Anthropology of Performance, New York: PAJ Publications, 1988

VIDAL, L. - Morte e Vida de uma Sociedade Indigena Brasileira, São Paulo: Hucitec/Edusp, 1977.

VIDAL, L.(org.) - Grafismo Indigena, Estudos de Antropologia Estética, São Paulo: Studio Nobel/FAPESP/ Edusp, 1992

- As artes indígenas e seus múltiplos mundos. In: Revista do Patrimônio Histórico e Artístico Nacional, n²9, Brasilia:IPHAN, 2001 